\title{
Aspirin Adherence, Aspirin Dosage, and C-Reactive Protein in the First Three Months after an Acute Coronary Syndrome
}

\author{
Ian M. Kronish, MD, MPH${ }^{\star}$, Nina Rieckmann, $\mathrm{PhD}^{\dagger}, \neq$, Daichi Shimbo, MD§, Matthew Burg, \\ $\mathrm{PhD}^{\S}$, and Karina W. Davidson, PhD§ \\ "Division of General Internal Medicine, Mount Sinai School of Medicine, New York, NY \\ †Berlin School of Public Health, Charité Medical Center, Berlin, Germany \\ ‡Department of Psychiatry, Mount Sinai School of Medicine, New York, NY \\ $\S$ Department of Medicine, Columbia University College of Physicians and Surgeons, New York, \\ NY
}

\begin{abstract}
Persistent elevation of inflammatory markers such as C-reactive protein (CRP) is associated with increased risk of recurrent cardiac events after acute coronary syndromes (ACS). There is conflicting evidence as to whether aspirin can reduce CRP after ACS. We investigated whether dosage and adherence to aspirin was associated with CRP 3 months after ACS. Adherence to aspirin was monitored using an electronic chip stored in a pill bottle cap for 3 months in a cohort of 105 patients enrolled within one week of an ACS. CRP was measured at baseline and 3 months. Logistic regression was used to test whether poor adherence to aspirin and lower aspirin dosage were associated with increased CRP levels, controlling for age, ACS type, disease comorbidity, baseline CRP, use of clopidogrel and statins, depressive symptoms, smoking, and adherence to other medications. Aspirin adherence was inversely correlated with CRP at 3 months (Spearman's $\mathrm{r}=-0.36, \mathrm{p}<.001)$. In the adjusted model, every $10 \%$ decrease in aspirin adherence was associated with 1.7 (95\% CI 1.2-2.4) increased odds of CRP $\geq 3.0 \mathrm{mg} / \mathrm{l}$ at 3 months; and low-dose aspirin was associated with $7.1(95 \% \mathrm{CI} 1.5-33.3)$ increased odds of CRP $\geq 3.0 \mathrm{mg} / \mathrm{l}$. Charlson comorbidity index, depressive symptoms, and baseline CRP were also predictive of CRP $\geq 3.0 \mathrm{mg} / \mathrm{l}$ at 3 months. The association between aspirin adherence and CRP was not attenuated by controlling for other risk reducing behaviors. In conclusion, there is a strong association between aspirin adherence and CRP post-ACS.
\end{abstract}

\section{Keywords}

aspirin; C-reactive protein; inflammation; acute coronary syndrome

(C) 2010 Excerpta Medica, Inc. All rights reserved.

Address for Correspondence: Karina W. Davidson, PhD, Department of Medicine, Columbia University College of Physicians and Surgeons, 622 W 168th St, PH9 Center, Room 948, New York, NY 10032 (kd2124@ columbia.edu); phone: 212-342-4493; fax: 212-342-3431.

Publisher's Disclaimer: This is a PDF file of an unedited manuscript that has been accepted for publication. As a service to our customers we are providing this early version of the manuscript. The manuscript will undergo copyediting, typesetting, and review of the resulting proof before it is published in its final citable form. Please note that during the production process errors may be discovered which could affect the content, and all legal disclaimers that apply to the journal pertain. 


\section{Background}

The amount of exposure to aspirin may be associated with C-reactive protein (CRP) levels after acute coronary syndromes (ACS). $1^{-} 6$ Accordingly, we tested whether lower adherence to aspirin and/or lower prescribed aspirin dosage in the 3 months after hospitalization for an ACS were associated with higher CRP levels at 3 months. Aspirin adherence was assessed using an electronic medication monitor. As adherence to aspirin may be a proxy for adherence to other medications that are more definitively linked with anti-inflammatory effects, we also explored the association between aspirin adherence and CRP level after controlling for self-reported adherence to medications in general.

\section{Methods}

This study was performed as part of the Coronary Psychosocial Evaluation Study (COPES), a series of multi-site observational cohort studies that examine the relationship between depression and prognosis after ACS.7 Briefly, between May 1, 2003 and April 15, 2005, a cohort of patients was recruited from 3 academic hospitals (Yale-New Haven Hospital and Hospital of St. Raphael in New Haven CT; Mount Sinai Medical Center in New York City) within 1 week of hospitalization for an ACS. The study defined ACS as either acute myocardial infarction (MI) or unstable angina using standard criteria8, and required patients to have symptoms consistent with acute myocardial ischemia and at least 1 of the following: ischemic electrocardiographic changes, angiogram indicative of coronary artery disease on current admission, documented history of coronary artery disease, or acute rise in serum troponin levels above the laboratory cutoff of each hospital. A study cardiologist confirmed ACS eligibility for all patients. An additional eligibility criteria was a score on the Beck Depression Inventory (BDI) of $\leq 4$ or $\geq 10$, ranges selected in the parent study to delineate non-depressed and depressed patients at baseline. Patients were excluded if they lived in a nursing home, exhibited cognitive impairment, or engaged in alcohol or substance abuse. All patients gave informed consent prior to enrollment. The study was approved by the Institutional Review Boards at each hospital.

Upon hospital discharge, patients who were prescribed a daily dose of aspirin $(81 \mathrm{mg}$, $162 \mathrm{mg}$, or $325 \mathrm{mg}$ ) and who were willing to have their aspirin adherence monitored by an electronic chip in the cap of their pill bottle were provided with a 90-day supply of their prescribed aspirin in a MEMS (Medication Event Monitoring System; APREX Corp, Fremont, CA) bottle. The MEMS device records the date and time whenever the bottle cap is opened. MEMS data were collected continuously over the next 3 months. The percentage of days the bottle cap was opened the correct number of times (once a day) was calculated.

Patients also provided blood samples in hospital and after 3 months for measurement of CRP. After centrifugation, serum samples were stored in aliquot portions at $-70^{\circ} \mathrm{C}$. Samples were shipped to a core laboratory (Specialty Laboratories, Valencia, California, USA) for analysis of high sensitivity CRP concentrations. The limit of detection of the CRP assay was $0.01 \mathrm{mg} / \mathrm{L}$; the analytical measurable range was $0.2-160 \mathrm{mg} / \mathrm{L}$; and the inter- and intra-assay coefficient of variation was $<8 \%$. Concentrations were determined by turbitometry (Bayer Diagnostics, Leverkusen, Germany).

One hundred seventy-two patients agreed to have their adherence monitored using MEMS. Details regarding enrollment into this substudy have been described elsewhere.9 One hundred and five of these patients $(61 \%)$ had blood samples drawn at baseline and 3 months. Patients who refused the blood draw did not significantly differ $(p>0.20)$ from patients who agreed with respect to sociodemographics, depression score, and clinical factors. A CRP of 
$\geq 3 \mathrm{mg} / \mathrm{l}$ was defined as elevated, as this identifies increased risk for recurrent events and death.

Baseline demographics, discharge medications, and clinical variables, including the constituents of the Charlson comorbidity index, a validated measure of risk for death in patients with chronic illness, 10 were obtained by patient interview and chart abstraction at the time of enrollment. Participants completed the BDI, a validated self-report instrument that has been used in prior studies of depression and ACS, and that predicts post-ACS eventfree survival.11

At 3 month follow-up, patients returned the MEMS cap and were asked about their adherence to cardiovascular risk lowering behaviors, included whether they had (1) smoked tobacco products in the last 7 days; (2) participated in a cardiac rehabilitation program; (3) exercised regularly; and/or (4) modified their diet to be heart healthy. In addition, patients were asked about their adherence to their medications using the Morisky scale; a self-report tool that has good agreement with objective measures of medication adherence.12 The scale is comprised of 4 items, each of which is scored as either 0 (adherent) or 1 (non-adherent). Total score is calculated by summation to obtain a total score between 0 and 4 . Patients with a score from 0 to 1 were categorized as having good medication adherence, whereas patients with a score from 2 to 4 were categorized as having poor medication adherence.

CRP was log transformed so that it was normally distributed. Spearman's correlation was used to assess the association between monitored aspirin adherence and CRP at 3-months. Chi square and t-tests were used to compare differences in patient characteristics between patients with and without elevated CRP, using a cutoff of $3 \mathrm{mg} / \mathrm{l}$. Logistic regression was then used to determine whether adherence to aspirin and aspirin dosage were independently associated with CRP level ( $\geq 3 \mathrm{mg} / \mathrm{l}$ versus $<3 \mathrm{mg} / \mathrm{l})$. Using linear regression, we also tested whether aspirin dosage and aspirin adherence were independently associated with a continuous measure of CRP. Models were adjusted for age13; ACS type14 (UA versus MI); Charlson Comorbidity index 10; baseline CRP; statin and plavix use; smoking status15; and depressive symptom severity (BDI score) at baseline.16,17 Analyses were also adjusted for self-reported adherence to overall medications as measured by the Morisky scale. 12 The $a$ priori choice of predictors was based on a review of the literature for important factors that may be associated with CRP after ACS. Finally, we used t-tests to determine whether adherence to aspirin was associated with aspirin dosage $(81 \mathrm{mg}$ versus $162 \mathrm{mg}$ or $325 \mathrm{mg}$ ) and with self-reported exercise, following a heart healthy diet, and attending cardiac rehabilitation. All statistical analyses were performed using SPSS 13 (Chicago, Inc.).

\section{Results}

Baseline and 3-month blood samples and MEMS-assessed aspirin adherence were available for 105 patients. The mean age of this sample was 59 (range 25-83), $47 \%$ were women, $87 \%$ were Caucasian, and 6\% self-identified as Hispanic. The index ACS event was ST elevation MI for $24 \%$ of patients, non-ST elevation MI for $30 \%$ of patients, and unstable angina for $47 \%$ of patients. The mean adherence to aspirin (\% days aspirin taken correctly) was $87 \%$, (range $23 \%-100 \%$ ), and $24 \%$ of patients took their aspirin on $<80 \%$ of days monitored.

Compared to patients with lower CRP level $(<3 \mathrm{mg} / \mathrm{l})$, patients with higher CRP level $(>3 \mathrm{mg} / \mathrm{l})$ at 3 months were more likely $(\mathrm{p}<.05)$ to have higher baseline Charlson comorbidity and BDI depressive symptom scores; and to have higher baseline CRP (Table 1). In contrast, patients with higher CRP level at 3 months were less likely to be discharged 
on clopidogrel or statins, though these differences were only statistically significant for statins.

Twenty-one patients (20\%) were discharged on low dose aspirin (81 mg daily), and 83 patients $(79 \%)$ were discharged on high dose aspirin (325mg daily). One patient was discharged on $162 \mathrm{mg}$ daily and was included in the high dose group. A greater proportion of patients hospitalized for MI were prescribed high dose aspirin at discharge as compared to patients hospitalized for UA (92\% vs 67\%, respectively, $\mathrm{p}=.002)$. Patients discharged on low dose aspirin had significantly higher CRP at 3 months than patients prescribed high dose aspirin even though low dose aspirin patients had lower CRP at baseline (Figure 1). In an adjusted analysis, low dose aspirin was associated with 7.1 (95\% CI 1.5 - 33.3) increased odds of CRP $\geq 3.0 \mathrm{mg} / \mathrm{l}$ at 3 months (Table 2). Aspirin adherence did not significantly differ between patients prescribed low versus high dose aspirin.

There was a dose-response relationship between increasing level of aspirin adherence and decreasing CRP concentration at 3 months (Figure 2). Adherence to aspirin by MEMS over 3 months was inversely correlated with CRP at 3 months (Spearman's $\mathrm{r}=-0.36, \mathrm{p}<.001$ ). In an adjusted model, aspirin adherence was a significant predictor of CRP (Table 2); for every 10 percent decrease in aspirin adherence, the odds of elevated CRP level at 3 months increased by 1.7 -fold (95\% CI 1.2 - 2.4). Higher Charlson score, baseline depressive symptom severity, baseline CRP, and lower aspirin dosage also predicted elevated CRP levels in this model.

Setting a cut-off for poor adherence to aspirin at less than $80 \%$, a greater proportion of patients with poor adherence had elevated CRP at 3 months than patients with good adherence (79.2\% vs. $33.3 \%, \mathrm{p}<.001)$. In the adjusted model controlling for the same factors, patients with poor adherence to aspirin had 7.6 (95\% CI 1.9 - 30.3) greater odds of having an elevated CRP level at 3 months. Using continuous (log transformed) CRP scores as the outcome, instead of a categorical CRP cut-off, did not substantially alter the association between aspirin adherence and CRP. However, Charlson score and aspirin dosage were no longer significant predictors of CRP elevation in this linear regression model (data not shown).

Aspirin adherence was not associated with self-reports of adhering to a heart healthy diet $(\mathrm{p}=0.74)$ or attending cardiac rehabilitation $(\mathrm{p}=0.93)$. There was, however, a significant correlation between adherence to aspirin by MEMS and adherence to overall medications as measured by the self-report Morisky scale (Spearman's r=.29, p=.003). Aspirin adherence was also higher among patients who self-reported not smoking and exercising regularly $(\mathrm{p}=$ 0.03 and 0.03 , respectively). Controlling for these behaviors did not significantly change the strength of the association between aspirin adherence and CRP at 3 months.

\section{Discussion}

The current analyses demonstrate a strong, independent association between adherence to aspirin and CRP in the first 3 months after ACS. This supports the hypothesis that aspirin has direct anti-inflammatory effects, separate from its anti-platelet effects, and that these anti-inflammatory effects are maximized with optimum adherence to aspirin. The plausibility of an anti-inflammatory effect from aspirin is supported by preclinical data showing that aspirin may have inhibitory effects on the activity of nuclear factors required for the expression of genes encoding pro-inflammatory molecules. 18,19 The likelihood that aspirin has direct anti-inflammatory effects is further supported by our data showing an association between higher aspirin dosage and lower CRP at 3 months. The optimal dose of 
aspirin after ACS remains unclear20; these data suggest there may be a biological rationale for using high dose aspirin.

An alternative explanation for the strong relationship between aspirin adherence and CRP is that adherence to aspirin may be representative of medication adherence more broadly, or to adherence with a range of risk reducing behaviors associated with lower CRP levels in other studies. $21 \mathrm{We}$ tested for this possibility by comparing electronically-monitored aspirin adherence with self-reported adherence to overall medications and other heart healthy behaviors. We found a weak correlation between electronically-monitored adherence to aspirin and self-reported adherence to medications. This is consistent with research showing that adherence to one medication does not necessarily correlate closely with adherence overall.22 A direct test of this explanation, however, would require objective adherence monitoring to either the full range of medications prescribed post-ACS, or specifically to those medications with known anti-inflammatory effects. There were significant associations between aspirin adherence and self-reported smoking and exercising at 3 months; yet, analyses adjusting for these behaviors did not substantially alter the association between aspirin adherence and CRP level. This strengthens the likelihood that aspirin directly mediates CRP levels.

Another interesting finding is that depression was associated with elevated CRP even after adjusting for aspirin adherence and medical comorbidity. This supports our earlier finding that patients with persistent depression 3 months after ACS were more likely to have persistently elevated CRP.17 The prognostic risk conferred by depression after ACS is well documented, but the cause of this increased risk remains uncertain.23,24 These data support an association between depression and increased inflammation that is, at least in part, independent of the influence that depression has on medication adherence.25,26

We did not find a significant association between being discharged on statin or clopidogrel and 3 month CRP level. Our study may have been underpowered to find statistical differences in these relationships. Alternatively, being discharged on these medications may not be representative of actually taking them. It is possible that patients discontinued or poorly adhered to these medications after discharge, effectively weakening the association between being discharged on these medications and CRP. A direct test of this explanation, however, would require objectively monitoring adherence to these medications.

There were several important limitations to our findings. First, the sample was relatively small, resulting in wide confidence intervals for some predictors of elevated CRP. Recruitment procedures could have led to a bias in the recruitment of subjects. The lack of an objective measure of adherence to other potentially important anti-inflammatory medications such as statins increases the possibility of confounding by adherence to these medications. Similarly, the assessment of health behaviors such as exercise was not obtained using objective tools.

Despite these limitations, we found a robust association between aspirin adherence in the first 3 months after ACS and CRP, even after controlling for multiple potential confounders. Whether this relationship is mediated directly through the biological activity of aspirin or whether it is an exemplar of broader adherence to prescribed medications and behaviors that reduce inflammation, the data illustrate the biological impact of poor adherence on inflammation. Poor adherence to medications is common in patients with cardiovascular disease27, and has been associated with recurrent cardiovascular events.28 Medication adherence is a potentially modifiable behavior that should be closely monitored in post-ACS patients. Future studies investigating the anti-inflammatory effects of aspirin or other drugs in post-ACS patients should include an assessment of medication adherence. 


\title{
Acknowledgments
}

\author{
None \\ Funding Sources
}

This work was supported by grants HC-25197, HL-076857, HL-088117, and HL-080665, HL-084034 from the $\mathrm{NIH}$, Bethesda, MD. There was no industry support for this work.

\section{References}

1. Feldman M, Jialal I, Devaraj S, Cryer B. Effects of low-dose aspirin on serum C-reactive protein and thromboxane B2 concentrations: a placebo-controlled study using a highly sensitive C-reactive protein assay. J Am Coll Cardiol. 2001; 37:2036-2041. [PubMed: 11419884]

2. Feng D, Tracy RP, Lipinska I, Murillo J, McKenna C, Tofler GH. Effect of short-term aspirin use on C-reactive protein. J Thromb Thrombolysis. 2000; 9:37-41. [PubMed: 10590187]

3. Fisher M, Cushman M, Knappertz V, Howard G. An assessment of the joint associations of aspirin and statin use with C-reactive protein concentration. Am Heart J. 2008; 156:106-111. [PubMed: 18585504]

4. Ikonomidis I, Andreotti F, Economou E, Stefanadis C, Toutouzas P, Nihoyannopoulos P. Increased proinflammatory cytokines in patients with chronic stable angina and their reduction by aspirin. Circulation. 1999; 100:793-798. [PubMed: 10458713]

5. Solheim S, Arnesen H, Eikvar L, Hurlen M, Seljeflot I. Influence of aspirin on inflammatory markers in patients after acute myocardial infarction. Am J Cardiol. 2003; 92:843-845. [PubMed: 14516890]

6. Woodward M, Lowe GD, Francis LM, Rumley A, Cobbe SM. A randomized comparison of the effects of aspirin and clopidogrel on thrombotic risk factors and C-reactive protein following myocardial infarction: the CADET trial. J Thromb Haemost. 2004; 2:1934-1940. [PubMed: 15550024]

7. Kronish IM, Rieckmann N, Halm EA, Shimbo D, Vorchheimer D, Haas DC, Davidson KW. Persistent depression affects adherence to secondary prevention behaviors after acute coronary syndromes. J Gen Intern Med. 2006; 21:1178-1183. [PubMed: 16899061]

8. Cannon CP, Battler A, Brindis RG, Cox JL, Ellis SG, Every NR, Flaherty JT, Harrington RA, Krumholz HM, Simoons ML, Van De Werf FJ, Weintraub WS, Mitchell KR, Morrisson SL, Brindis RG, Anderson HV, Cannom DS, Chitwood WR, Cigarroa JE, Collins-Nakai RL, Ellis SG, Gibbons RJ, Grover FL, Heidenreich PA, Khandheria BK, Knoebel SB, Krumholz HL, Malenka DJ, Mark DB, McKay CR, Passamani ER, Radford MJ, Riner RN, Schwartz JB, Shaw RE, Shemin RJ, Van Fossen DB, Verrier ED, Watkins MW, Phoubandith DR, Furnelli T. American College of Cardiology key data elements and definitions for measuring the clinical management and outcomes of patients with acute coronary syndromes. A report of the American College of Cardiology Task Force on Clinical Data Standards (Acute Coronary Syndromes Writing Committee). J Am Coll Cardiol. 2001; 38:2114-2130. [PubMed: 11738323]

9. Rieckmann N, Gerin W, Kronish IM, Burg MM, Chaplin WF, Kong G, Lesperance F, Davidson KW. Course of depressive symptoms and medication adherence after acute coronary syndromes: an electronic medication monitoring study. J Am Coll Cardiol. 2006; 48:2218-2222. [PubMed: 17161249]

10. Charlson ME, Pompei P, Ales KL, MacKenzie CR. A new method of classifying prognostic comorbidity in longitudinal studies: development and validation. J Chronic Dis. 1987; 40:373383. [PubMed: 3558716]

11. Strik JJ, Honig A, Lousberg R, Denollet J. Sensitivity and specificity of observer and self-report questionnaires in major and minor depression following myocardial infarction. Psychosomatics. 2001; 42:423-428. [PubMed: 11739910]

12. Morisky DE, Green LW, Levine DM. Concurrent and predictive validity of a self-reported measure of medication adherence. Med Care. 1986; 24:67-74. [PubMed: 3945130] 
13. Stowe RP, Peek MK, Cutchin MP, Goodwin JS. Plasma Cytokine Levels in a Population-Based Study: Relation to Age and Ethnicity. J Gerontol A Biol Sci Med Sci. 2009; 65:429-433. [PubMed: 20018825]

14. Ruckerl R, Peters A, Khuseyinova N, Andreani M, Koenig W, Meisinger C, Dimakopoulou K, Sunyer J, Lanki T, Nyberg F, Schneider A. Determinants of the acute-phase protein C-reactive protein in myocardial infarction survivors: the role of comorbidities and environmental factors. Clin Chem. 2009; 55:322-335. [PubMed: 19095729]

15. Bazzano LA, He J, Muntner P, Vupputuri S, Whelton PK. Relationship between cigarette smoking and novel risk factors for cardiovascular disease in the United States. Ann Intern Med. 2003; 138:891-897. [PubMed: 12779299]

16. Miller GE, Stetler CA, Carney RM, Freedland KE, Banks WA. Clinical depression and inflammatory risk markers for coronary heart disease. Am J Cardiol. 2002; 90:1279-1283. [PubMed: 12480034]

17. Shimbo D, Rieckmann N, Paulino R, Davidson KW. Relation between C reactive protein and depression remission status in patients presenting with acute coronary syndrome. Heart. 2006; 92:1316-1318. [PubMed: 16908705]

18. Cyrus T, Sung S, Zhao L, Funk CD, Tang S, Pratico D. Effect of low-dose aspirin on vascular inflammation, plaque stability, and atherogenesis in low-density lipoprotein receptor-deficient mice. Circulation. 2002; 106:1282-1287. [PubMed: 12208806]

19. Muller DN, Heissmeyer V, Dechend R, Hampich F, Park JK, Fiebeler A, Shagdarsuren E, Theuer J, Elger M, Pilz B, Breu V, Schroer K, Ganten D, Dietz R, Haller H, Scheidereit C, Luft FC. Aspirin inhibits NF-kappaB and protects from angiotensin II-induced organ damage. Faseb J. 2001; 15:1822-1824. [PubMed: 11481242]

20. Kong DF, Hasselblad V, Kandzari DE, Newby LK, Califf RM. Seeking the optimal aspirin dose in acute coronary syndromes. Am J Cardiol. 2002; 90:622-625. [PubMed: 12231088]

21. Chrysohoou C, Panagiotakos DB, Pitsavos C, Das UN, Stefanadis C. Adherence to the Mediterranean diet attenuates inflammation and coagulation process in healthy adults: The ATTICA Study. J Am Coll Cardiol. 2004; 44:152-158. [PubMed: 15234425]

22. Yeaw J, Benner JS, Walt JG, Sian S, Smith DB. Comparing adherence and persistence across 6 chronic medication classes. J Manag Care Pharm. 2009; 15:728-740. [PubMed: 19954264]

23. van Melle JP, de Jonge P, Spijkerman TA, Tijssen JG, Ormel J, van Veldhuisen DJ, van den Brink RH, van den Berg MP. Prognostic association of depression following myocardial infarction with mortality and cardiovascular events: a meta-analysis. Psychosom Med. 2004; 66:814-822. [PubMed: 15564344]

24. Lesperance F, Frasure-Smith N, Juneau M, Theroux P. Depression and 1-year prognosis in unstable angina. Arch Intern Med. 2000; 160:1354-1360. [PubMed: 10809041]

25. Carney RM, Freedland KE, Miller GE, Jaffe AS. Depression as a risk factor for cardiac mortality and morbidity: a review of potential mechanisms. J Psychosom Res. 2002; 53:897-902. [PubMed: 12377300]

26. Lett HS, Blumenthal JA, Babyak MA, Sherwood A, Strauman T, Robins C, Newman MF. Depression as a risk factor for coronary artery disease: evidence, mechanisms, and treatment. Psychosom Med. 2004; 66:305-315. [PubMed: 15184688]

27. Eagle KA, Kline-Rogers E, Goodman SG, Gurfinkel EP, Avezum A, Flather MD, Granger CB, Erickson S, White K, Steg PG. Adherence to evidence-based therapies after discharge for acute coronary syndromes: an ongoing prospective, observational study. Am J Med. 2004; 117:73-81. [PubMed: 15234641]

28. Ho PM, Magid DJ, Shetterly SM, Olson KL, Maddox TM, Peterson PN, Masoudi FA, Rumsfeld JS. Medication nonadherence is associated with a broad range of adverse outcomes in patients with coronary artery disease. Am Heart J. 2008; 155:772-779. [PubMed: 18371492] 


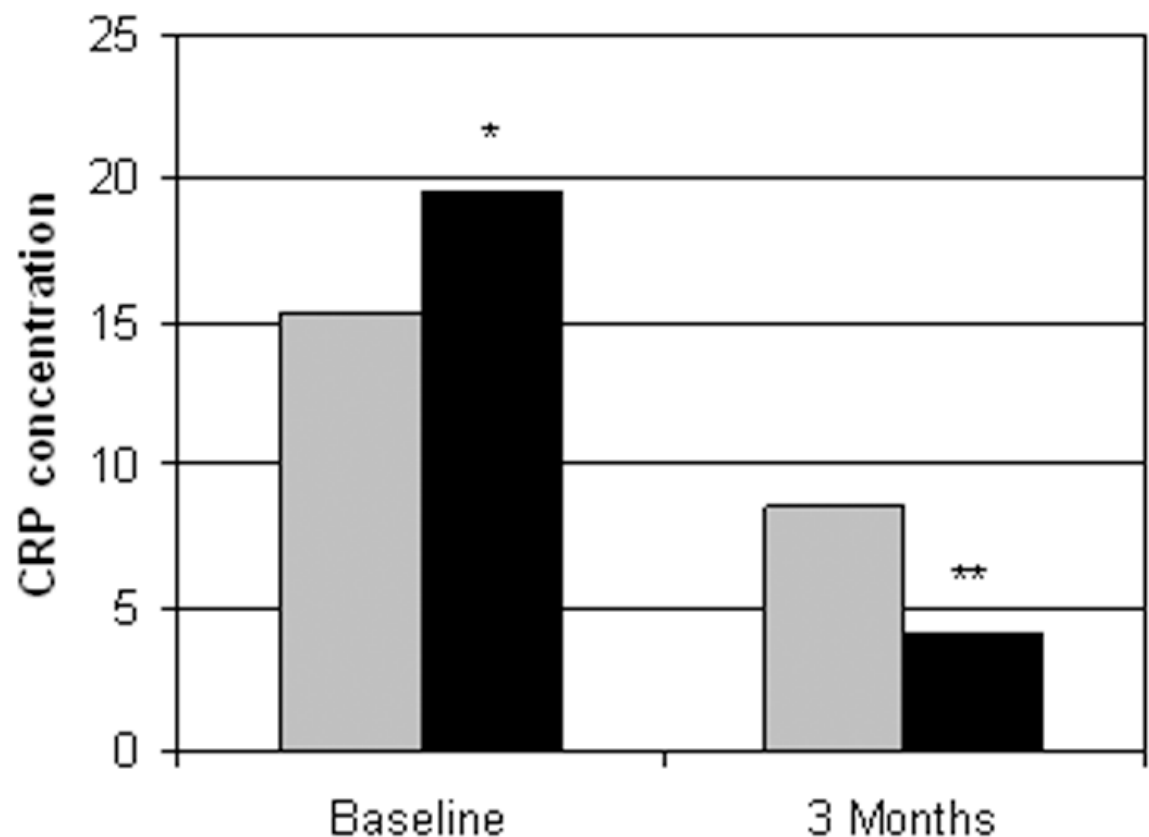

ASA $81 \mathrm{mg}$

ASA 325 or $162 \mathrm{mg}$

Baseline

3 Months

Figure 1.

Relation of aspirin dose and C-reactive protein (CRP) concentration during hospitalization for an acute coronary syndrome and 3 months later. Patients prescribed low-dose aspirin (81 $\mathrm{mg}$ ) had higher overall CRP concentrations at 3 months as compared to patients prescribed high-dose aspirin (162 $\mathrm{mg}$ or $325 \mathrm{mg}$ ).

Abbreviations: CRP, C-reactive protein; ASA, aspirin

$* \mathrm{p}=0.42$

$* * \mathrm{p}=0.02$ 


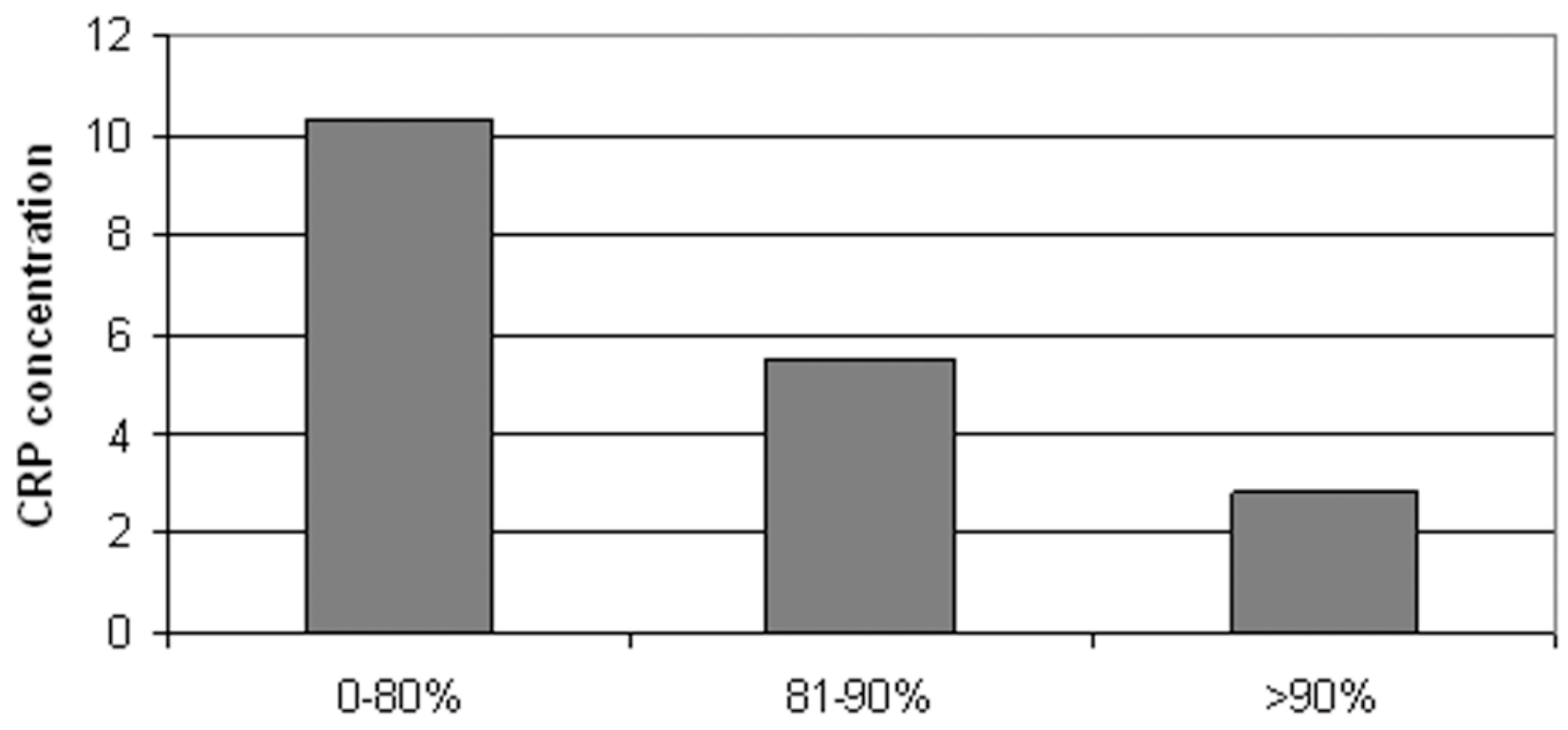

Aspirin adherence over 3 months

Figure 2.

Relation of mean aspirin adherence and C-reactive protein concentration 3 months after an acute coronary syndrome. There is a dose response relationship between aspirin adherence and CRP concentration with increasing adherence associated with decreasing CRP at 3 months.

Abbreviation: CRP, C-reactive protein 
Table 1

Baseline characteristics according to C-reactive protein level 3 months after acute coronary syndrome*

\begin{tabular}{lccc}
\hline Characteristic & $\begin{array}{c}\text { CRP } \leq \mathbf{3} \text { mg/l } \\
(\mathbf{N}=\mathbf{5 9})\end{array}$ & $\begin{array}{c}\text { CRP >3 mg/ } \\
(\mathbf{N = 4 6 )}\end{array}$ & p-value \\
\hline Age, mean (SD), (years) & $58.2(11.4)$ & $60.8(13.2)$ & 0.28 \\
ACS type, myocardial infarction & $35(59 \%)$ & $21(46 \%)$ & 0.16 \\
Charlson comorbidity index, mean (SD) & $0.7(0.9)$ & $1.7(1.7)$ & $<.001$ \\
BDI baseline, mean (SD) & $5.6(6.2)$ & $11.3(8.7)$ & $<.001$ \\
CRP baseline, mean (SD) & $13.8(18.4)$ & $25.0(23.3)$ & 0.01 \\
Smoking at 3 months & $8(14 \%)$ & $7(15 \%)$ & 0.81 \\
Discharged on statin & $55(93 \%)$ & $36(78 \%)$ & 0.03 \\
Discharged on clopidogrel & $52(88 \%)$ & $35(76 \%)$ & 0.10 \\
Good adherence to overall medications & $49(83 \%)$ & $36(78 \%)$ & 0.54 \\
Prescribed low dose aspirin (81 mg) & $7(12 \%)$ & $14(30 \%)$ & 0.02 \\
Aspirin adherence 0-3mo, mean (SD) & $91.6(13.3)$ & $80.8(17.9)$ & 0.001 \\
\hline
\end{tabular}

* Abbreviations: CRP, C-reactive protein; ACS, acute coronary syndrome; BDI, Beck Depression Inventory score 
Table 2

Unadjusted and adjusted* odds ratios for predictors of elevated C-reactive protein level (CRP >3 mg/l) 3 months after acute coronary syndrome ${ }^{\dagger}$

\begin{tabular}{|c|c|c|}
\hline Predictor & Unadjusted OR (95\% CI) & Adjusted OR (95\% CI) \\
\hline Age & $1.02(0.99-1.05)$ & $0.98(0.93-1.04)$ \\
\hline CRP concentration at baseline & $1.03(1.01-1.05)$ & $1.04(1.01-1.07)$ \\
\hline ACS type, myocardial infarction & $0.58(0.26-1.26)$ & $1.08(0.29-4.01)$ \\
\hline Charlson comorbidity index & $1.99(1.32-2.99)$ & $1.96(1.12-3.41)$ \\
\hline Discharged on statin & $0.26(0.08-0.90)$ & $0.32(0.05-2.02)$ \\
\hline Discharged on clopidogrel & $0.43(0.15-1.21)$ & $0.99(0.16-6.21)$ \\
\hline Smoker at 3 months & $1.14(0.38-3.43)$ & $0.68(0.14-3.42)$ \\
\hline BDI score at baseline & $1.11(1.05-1.18)$ & $1.16(1.07-1.26)$ \\
\hline Poor adherence to medications overall (Morisky score) & $1.36(0.51-3.61)$ & $0.97(0.15-6.37)$ \\
\hline Prescribed low dose aspirin $(81 \mathrm{mg})$ at discharge & $3.22(1.19-9.09)$ & $7.14(1.54-33.33)$ \\
\hline Poor adherence to aspirin (continuous per 10 percent decrease) & $1.65(1.20-2.27)$ & $1.65(1.15-2.35)$ \\
\hline
\end{tabular}

* Model adjusted for age, C-reactive protein at baseline, type of acute coronary syndrome (unstable angina is the reference group), comorbidity (Charlson score), smoking status at three months, discharge medications (statin, clopidogrel), depressive symptom severity (BDI score), adherence to medications (Morisky score), and aspirin dosage (high dose aspirin $162 \mathrm{mg}$ or $325 \mathrm{mg}$ is the reference group)

${ }^{\dagger}$ Abbreviations: OR, odds ratio; CRP, C-reactive protein concentration; ACS, acute coronary syndromes; BDI, Beck Depression Inventory ${ }_{\mathrm{p}}^{+}<0.05$ 